\title{
Inhibition and decay of motor and nonmotor priming
}

\author{
UWE MATTLER \\ Otto-von-Guericke Universität Magdeburg, Magdeburg, Germany
}

\begin{abstract}
Motor responses can be facilitated by congruent visual stimuli and prolonged by incongruent visual stimuli that are made invisible by masking (direct motor priming). Recent studies on direct motor priming showed a reversal of these priming effects when a three-stimulus paradigm was used in which a prime was followed by a mask and a target stimulus was presented after a delay. A similar three-stimulus paradigm on nonmotor priming, however, showed no reversal of priming effects when the mask was used as a cue for processing of the following target stimulus (cue priming). Experiment 1 showed that the time interval between mask and target is crucial for the reversal of priming. Therefore, the time interval between mask and target was varied in three experiments to see whether cue priming is also subject to inhibition at a certain time interval. Cues indicated (1) the stimulus modality of the target stimulus, (2) the task to be performed on a multidimensional auditory stimulus, or (3) part of the motor response. Whereas direct motor priming showed the reversal of priming about $100 \mathrm{msec}$ after mask presentation, cue priming effects simply decayed during the $300 \mathrm{msec}$ after mask presentation. These findings provide boundary conditions for accounts of inverse priming effects.
\end{abstract}

An increasing number of recent studies have shown behavioral and psychophysiological effects of visual stimuli that are made invisible by masking (Abrams \& Greenwald, 2000; Dehaene et al., 1998; Eimer, 1999; Eimer \& Schlaghecken, 1998; Greenwald, Draine, \& Abrams, 1996; Klinger, Burton, \& Pitts, 2000; Klotz \& Neumann, 1999; Leuthold \& Kopp, 1998; Mattler, 2003; Naccache \& Dehaene, 2001a, 2001b; Neumann \& Klotz, 1994; Schmidt, 2000, 2002; Vorberg, Mattler, Heinecke, Schmidt, \& Schwarzbach, 2003; Wentura, 2000; Wolff, 1989). One of the first studies was conducted by Fehrer and Raab (1962), who presented a square that was followed by two flanking squares after varying stimulus onset asynchronies (SOAs). When participants were to respond as soon as a stimulus appeared, simple reaction time (RT) was virtually independent of SOA, although verbal reports of stimulus visibility changed with SOA (see Neumann \& Klotz, 1994).

This dissociation was confirmed and extended by recent work that also employed metacontrast masking to manipulate stimulus visibility. In metacontrast masking, the visibility of a briefly flashed prime stimulus is reduced by a following spatially flanking masking stimulus (Breitmeyer, 1984). Wolff (1989) and Neumann and Klotz (1994) found that choice RTs to the mask are shortened or prolonged if primes share stimulus attributes with masks that are critical for the correct or the alterna-

I thank Dirk Vorberg for stimulating discussions, reviewers Bruce Milliken and Bernhard Hommel for helpful suggestions, and Jessica Arnswald and Nico Brunzeck for collecting the data. Correspondence should be addressed to U. Mattler, Fakultät für Naturwissenschaften, Department of Neurology II, Otto-von-Guericke Universität Magdeburg, Leipziger Strasse 44, D-39016 Magdeburg, Germany (e-mail: uwe. mattler@medizin.uni-magdeburg.de). tive response, respectively (see Klotz \& Neumann, 1999). Electrophysiological evidence from event-related potentials measured over the motor cortex suggests that primes can activate specific responses at the motor cortex (Dehaene et al., 1998; Eimer, 1999; Eimer \& Schlaghecken, 1998; Leuthold \& Kopp, 1998).

A simple change of the direct motor priming paradigm leads to a surprising change of priming effects. Eimer and Schlaghecken (1998) used a three-stimulus paradigm in which the mask and the target are separate stimuli and found faster responses on incongruent than on congruent trials (Eimer, 1999; Eimer \& Schlaghecken, 1998; Klapp \& Hinkley, 2002; Schlaghecken \& Eimer, 2000, 2002; Vorberg, 1998). However, not every threestimulus paradigm leads to a reversal of priming effects. Mattler (2003) used a three-stimulus paradigm to study cue priming effects. In these experiments, the prime was also followed by a mask that was followed by a target stimulus. Participants had to use the mask as a cue for the processing of the following target. In this way, the mask cued the modality of a target stimulus (visual vs. auditory), the cognitive task to be performed on a target stimulus (pitch discrimination vs. timbre discrimination), or part of the required motor response (left or right hand). In contrast to the experiments on direct motor priming that used the three-stimulus paradigm, there was no evidence for a reversal of priming effects in the cue priming experiments. Instead, in each of these experiments, congruent primes increased speed and accuracy of the response, whereas incongruent primes slowed responses and increased the error rate (Mattler, 2003).

Although a three-stimulus paradigm was used in direct motor priming and in cue priming, different priming effects might have resulted due to differences between 
the two paradigms. First, inverse priming effects might have occurred with direct motor priming because the target is associated to a specific motor response in this paradigm and primes might therefore have a direct impact on motor activation. This might have the potential to trigger an inhibitory mechanism that leads to the inverse priming effect. This inverse priming effect might be absent in cue priming because primes cannot affect motor activation directly. Second, inverse priming effects might have occurred with direct motor priming because the second stimulus is a task-irrelevant stimulus that has to be ignored. In contrast, the mask used in the cue priming paradigm is task relevant because it has to be used as a cue to process the following target stimulus. Different priming effects could result if the inhibitory mechanism is triggered only by taskirrelevant stimuli (see the General Discussion).

Third, the reversal of the cue priming effect might have been absent in cue priming because the temporal interval between the second and the third stimulus was inappropriate. Both electrophysiological and behavioral data showed that the interval between the second and the third stimulus is a crucial factor for the reversal of priming effects in direct motor priming. Electrophysiological evidence from event-related potentials measured over the motor cortex showed that response inhibition follows after response facilitation (Eimer, 1999; Eimer \& Schlaghecken, 1998). An early effect of primes consisted in greater activation of the motor cortex that controls the motor response associated to the prime. This initial effect was then reversed, leading to a stronger activation of the motor cortex that controls the alternative motor response. Corresponding to this pattern of effects at levels of the motor cortex, RT was facilitated on incompatible trials but prolonged on compatible trials, leading to the reversal of direct motor priming effects. The importance of the interval between the neutral mask and target presentation for the reversal of the priming effect was confirmed by behavioral studies (Eimer, 1999; Vorberg, 1998). With mask-target SOA below $50 \mathrm{msec}$, regular priming effects occurred; with longer SOAs, priming effects reversed (e.g., Eimer, 1999).

Thus, electrophysiological and behavioral findings strongly suggest that activation is followed by inhibition after a certain time. Therefore, it is possible that previous experiments on cue priming did not show an inverse priming effect because the interval between mask and target was inappropriate to obtain the effect of the inhibitory mechanism. In a first attempt to understand the conditions that lead to inverse priming effects in the three-stimulus paradigm, the present study examined whether cue priming effects reverse when the SOA between mask and target is appropriate. To this end, the present experiments varied the SOA between the mask and the target stimulus and compared the effect of this manipulation in direct motor priming and in cue priming.

The hypothesis that a similar interaction of activation and inhibition might lead to reversed priming effects with cue priming accords with recent theories of selective attention that incorporate both activation and inhi- bition. These theories aim to explain how goal-relevant information is selected in the context of goal-irrelevant information, and it has been found useful to assume an enhancing effect of goal-relevant information and an impeding effect of irrelevant information (for a review, see Milliken \& Tipper, 1998). An effect of inhibitory processes has been invoked in these theories to account for several empirical phenomena, such as attentional blink (Raymond, Shapiro, \& Arnell, 1992), repetition blindness (Kanwisher, 1987), or negative priming (Tipper, 1985).

A functional model of selective attention was suggested by Houghton and Tipper (1994) that specifies the role of inhibitory processes in gating perceptual information to motor processes. According to this model, attention operates on object representations prior to their effect on response activation. Response activation is subject to the competing impact of relevant and irrelevant sensory information. To ensure that responses are controlled by relevant information instead of distractors, facilitatory and inhibitory attentional mechanisms control the impact of sensory information on the motor system. For the present purpose, the explicit assumption is of special interest that inhibition operates at levels of processing that are located before the motor level. It was reasoned that if inhibitory mechanisms control nonmotor processing, inhibition might affect nonmotor priming in the same way that it affects direct motor priming.

\section{The Present Study}

The present study had two objectives. First, the study examined whether inverse priming effects can be found in the cue priming paradigm with a proper time interval between the second and the third stimulus. Experiment 1 was intended to find the point in time at which direct motor priming effects reverse with the present stimuli. To this end, the SOA between mask and target was varied in small steps over a range of about $.5 \mathrm{sec}$. The following three experiments investigated whether the three-stimulus paradigm used in cue priming also leads to inhibition of priming effects with a certain SOA between mask and target. Second, because direct and indirect motor priming effects were comparable to nonmotor priming effects in a prior study (Mattler, 2003), it seemed beneficial to investigate whether the time interval between the mask and the target affects indirect motor priming and nonmotor priming in the same way. Therefore, the same paradigm was used across three experiments, two on nonmotor priming and one on indirect motor priming.

\section{EXPERIMENT 1 Inhibition of Direct Motor Priming}

In direct motor priming experiments, primes affect responses to target stimuli with which they share critical attributes. RTs to the target are shortened or prolonged if primes share stimulus attributes with the target that are critical for the correct or the alternative response, respectively. These priming effects are also found in a twostimulus paradigm in which the target stimulus is a mask 
for the prime, leading to priming without awareness of the effective stimulus (e.g., Vorberg et al., 2003). However, inverse priming effects are found when a threestimulus paradigm is used in which the prime is followed by a neutral mask, followed by a separate target stimulus after a delay of several milliseconds: Response speed and accuracy increase on inconsistent trials over consistent trials (Eimer, 1999; Eimer \& Schlaghecken, 1998; Klapp \& Hinkley, 2002; Schlaghecken \& Eimer, 2000, 2002; Vorberg, 1998). Two factors seem to be critical to observe the inhibitory priming effect: A three-stimulus paradigm has to be used in which the masking stimulus follows the prime prior to target presentation, and the target has to follow the mask after a sufficient delay (e.g., Eimer, 1999; Vorberg, 1998).

Experiment 1 was an attempt to examine the time course of the inhibition of direct motor priming by varying the time interval between mask and target stimulus. On each trial, a prime was presented briefly, followed after a variable SOA by a neutral mask at the same location. The target stimulus followed the mask after another variable SOA. The effect of masked primes was assessed by the effects of prime-target congruency on RT. Prime and target stimuli were "congruent" when they had the same outer shape and "incongruent" otherwise (Figure 1). Priming was assessed by the RT advantage on congruent over incongruent trials. The time course of priming was determined by the extent of priming at different SOAs.

\section{Method}

Participants. Nine students from the University of Magdeburg ( 9 women) from 20 to 32 years of age ( $M=22.1$ years) participated in the experiment. All reported being right-handed, and all had normal or corrected-to-normal vision. Each participant took part in six 1-h sessions, receiving course credit for participation.

Tasks. Two tasks were employed. (1) During five sessions, the participants responded to the overall black outline of a diamond(square-) shaped target stimulus by pressing the left (right) ALT key on the keyboard with their left (right) index finger. (2) The entire sixth session was used to measure prime recognition performance. In this session, the participants were informed about the presence of primes and were to respond to the shape of primes without speed stress: They responded to a diamond- (square-) shaped prime stimulus with a left- (right-) hand response.

Stimuli. Stimuli similar to those introduced by Neumann and Klotz (1994) were used. Square- and diamond-shaped stimuli served as prime and target stimuli (Figure 1). The neutral mask was made by overlapping the square- and diamond-shaped stimuli (Figure 2). All stimuli were presented black on white, on a computer monitor at a refresh rate of $60 \mathrm{~Hz}$. Stimuli were positioned at the fixation cross in the center of the monitor. Squares and diamonds consisted of the same number of pixels. Prime squares and diamonds subtended visual angles of about $1.0^{\circ}$ and $1.5^{\circ}$ in height and width. Height and width of the outer contour of targets subtended about $1.6^{\circ}$ and $2.2^{\circ}$ of visual angle for square- and diamond-shaped masks, respectively. Primes were 1 pixel smaller than the inner outlet of the mask. Prime duration was $34 \mathrm{msec}$; the duration of the neutral mask was $51 \mathrm{msec}$. Prime-mask SOA (PM-SOA) varied randomly from trial to trial between $68 \mathrm{msec}$ and $119 \mathrm{msec}$. Primes were congruent with the target in half of the trials, with congruency varying randomly between trials. After a variable interval after the neutral mask, the target was presented for $102 \mathrm{msec}$. The mask-target SOA (MT-SOA) varied randomly from trial to trial in steps of $68 \mathrm{msec}$ from 0 to $544 \mathrm{msec}$. Note that with 0 -msec MT-SOA, the neutral mask was absent. An auditory stimulus with $1000-\mathrm{Hz}$ and 100-msec duration served as error feedback.

Procedure. The participants were tested individually in single sessions on separate days. In the choice RT task, they were instructed to focus the fixation stimulus, to ignore the neutral mask, and to respond as quickly as possible, without making errors. The stimulus sequence is given in Figure 2. Trials started with the fixation cross, followed by the prime, which was then followed by the neutral mask, both positioned at fixation. The interval between fixation and the mask was $780 \mathrm{msec}$, and the prime preceded the neutral mask with 68- or 119-msec SOA. In this way, the interval between fixation cross and the neutral mask was constant while the interval between fixation and prime varied unpredictably. Responses were given by pressing the appropriate response button with the left or right index finger. The computer monitored for a response within $2 \mathrm{sec}$ after target onset. For wrong responses, auditory feedback was given after this period, followed by a rest of $2 \mathrm{sec}$. The warning signal for the next trial appeared after a random interval with a mean of 1,500 msec. Summary feedback (mean RT, percentage correct) was given at the end of each session.

At the beginning of the session with the direct prime recognition task, the prime and neutral mask were shown to the participants with long stimulus durations and long interstimulus intervals. This slow demonstration of the stimuli ensured that participants understood the task and recognized the perceptual interaction between

\section{Congruent}
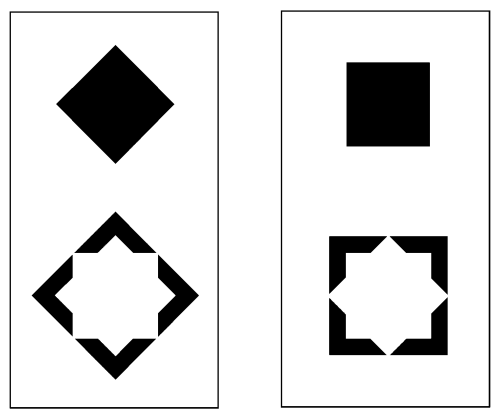

Incongruent

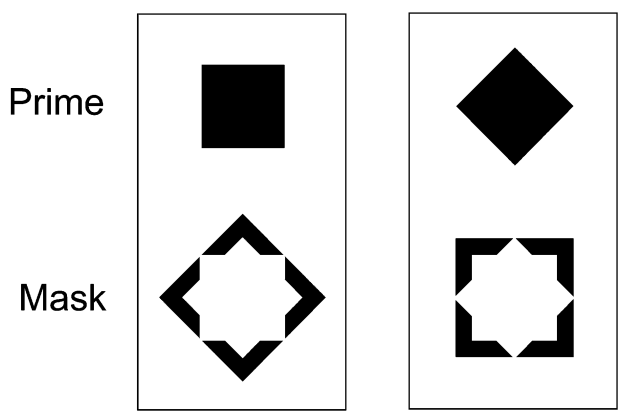

Figure 1. Stimuli used for metacontrast masking in all experiments. On half the trials, primes were congruent to masks. In Experiment 1, the mask served as the target, and a neutral stimulus was presented after the prime and before the mask. In the other experiments, the mask served as the cue. Note that one prime-mask pair was presented on each trial. 


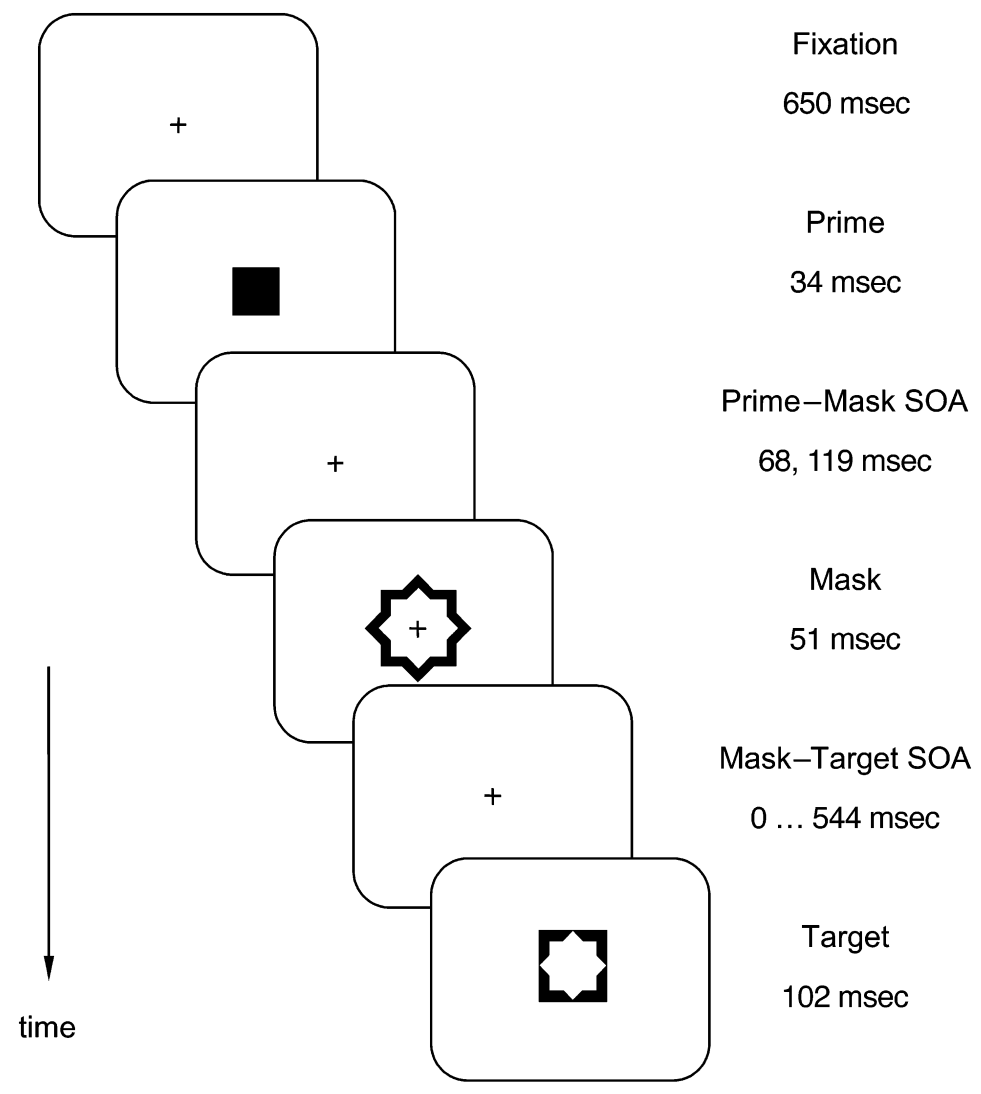

Figure 2. Schematic diagram of stimulus events in Experiment 1. In the choice RT task, the participant responded to the target stimulus presented after the neutral mask. Priming effects were assessed by the effects of prime-target congruency on RT. In the prime recognition task, participants reported the prime. The time course of priming was assessed by varying the stimulus onset asynchrony (SOA) between prime and neutral mask and between mask and target randomly from trial to trial.

the prime and the mask. They were instructed to identify the primes as accurately as possible with ample time. The computer monitored for a response within $6 \mathrm{sec}$ after mask onset. As in the choice RT task, auditory feedback was provided on error trials, and summary feedback (mean RT, percentage correct) was given at the end of the session. Note that prime recognition was measured in a single session because it was assumed that PM-SOA should be the only factor that affects prime recognition performance. Therefore, it was reasoned that a single session would provide sufficient data for an analysis of the two levels of PM-SOA. Nonetheless, all levels of PM-SOA, congruency, and MT-SOA varied in the same manner as in choice RT sessions.

Design. The effect of primes on RT was determined by comparing mean RTs of congruent and incongruent trials. A practice session was followed by four sessions with the choice RT task, comprising 64 replications of each of the 36 conditions resulting from the combination of PM-SOA (two levels), MT-SOA (nine levels), and congruency (two levels). All combinations were presented in random order with the restriction that each of the 36 conditions was replicated 20 times in each session. Dependent variables were RT and error rates. Independent variables were PM-SOA, MT-SOA, and congruency.

Statistical analysis. The first block per session was considered warmup and was excluded from data analysis. Choice RTs were summarized by trimmed means (excluding the three slowest and the four fastest responses in each condition), determined for correct trials per subject and condition, excluding posterror trials. RT and error rates for the choice RT task were analyzed with a three-way repeated measures analysis of variance (ANOVA). Prime recognition performance was analyzed with an ANOVA with a factor PMSOA on the arc-sine transformed mean proportion correct, determined separately for each participant and target, and then averaged for each SOA condition. All reported $p$ values are based on GeisserGreenhouse corrected degrees of freedom, whereas, for the sake of readability, the stated degrees of freedom are uncorrected. Statistical analysis remained identical across experiments.

\section{Results}

Errors. Errors occurred on $0.7 \%$ of the trials, but no independent variable had a significant effect on arc-sin transformed error rates. For mean error rates, see Table 1.

RT. Congruency affected RT significantly, with slower responses on congruent $(460 \mathrm{msec})$ than on incongruent $(451 \mathrm{msec})$ trials $\left[F(1,8)=13.6, M S_{\mathrm{e}}=562\right.$, $p<.01]$. RT decreased with target delay, as reflected in the significant effect of MT-SOA $\left[F(8,64)=47.0, M S_{\mathrm{e}}=\right.$ $417, p<.001]$. This decrease in RT was modulated by PM-SOA, as reflected in the significant interaction of 
Table 1

Error Rates (Percent)

\begin{tabular}{|c|c|c|c|c|c|c|c|c|c|c|}
\hline \multirow{2}{*}{$\begin{array}{l}\text { PM-SOA } \\
(\mathrm{msec})\end{array}$} & \multirow{2}{*}{$\begin{array}{l}\text { Prime-Mask } \\
\text { Congruency }\end{array}$} & \multicolumn{9}{|c|}{ MT-SOA (msec) } \\
\hline & & 0 & 68 & 132 & 204 & 272 & 340 & 408 & 476 & 544 \\
\hline \multicolumn{11}{|c|}{ Experiment 1} \\
\hline \multirow[t]{2}{*}{64} & Congruent & 0.9 & 1.4 & 0.4 & 0.5 & 0.5 & 1.2 & 0.4 & 1.1 & 0.7 \\
\hline & Incongruent & 0.2 & 0 & 0.2 & 0.7 & 0.5 & 0.7 & 0.4 & 0.5 & 0.9 \\
\hline \multirow[t]{2}{*}{119} & Congruent & 0.7 & 1.9 & 0.7 & 0.5 & 1.1 & 0.5 & 1.2 & 0.9 & 0.9 \\
\hline & Incongruent & 0.4 & 0.2 & 0.4 & 0.9 & 0.7 & 0.7 & 1.4 & 0.7 & 0.9 \\
\hline \multicolumn{11}{|c|}{ Experiment 2} \\
\hline \multirow[t]{2}{*}{64} & Congruent & & 2.8 & 2.0 & 1.1 & 2.0 & 0.8 & 2.3 & 3.0 & 2.3 \\
\hline & Incongruent & & 4.2 & 1.7 & 1.1 & 2.2 & 2.2 & 1.9 & 1.9 & 2.3 \\
\hline \multirow[t]{2}{*}{119} & Congruent & & 1.9 & 1.6 & 1.9 & 1.7 & 2.8 & 3.1 & 2.3 & 2.5 \\
\hline & Incongruent & & 5.0 & 2.8 & 2.5 & 2.3 & 1.9 & 2.0 & 1.9 & 2.0 \\
\hline \multicolumn{11}{|c|}{ Experiment 3} \\
\hline \multirow[t]{2}{*}{64} & Congruent & & 3.4 & 3.2 & 2.5 & 2.5 & 3.4 & 2.7 & 1.8 & 2.9 \\
\hline & Incongruent & & 4.5 & 3.8 & 3.4 & 3.2 & 2.9 & 1.8 & 3.4 & 3.1 \\
\hline \multirow[t]{2}{*}{119} & Congruent & & 3.1 & 2.9 & 2.7 & 3.2 & 3.8 & 2.3 & 3.8 & 2.5 \\
\hline & Incongruent & & 5.6 & 3.4 & 2.5 & 2.5 & 2.7 & 2.7 & 2.3 & 3.1 \\
\hline \multicolumn{11}{|c|}{ Experiment 4} \\
\hline \multirow[t]{2}{*}{64} & Congruent & & 1.9 & 2.1 & 3.3 & 2.9 & 3.0 & 1.7 & 2.3 & 1.9 \\
\hline & Incongruent & & 3.3 & 3.8 & 2.1 & 2.3 & 2.1 & 1.9 & 0.6 & 2.3 \\
\hline \multirow[t]{2}{*}{119} & Congruent & & 2.3 & 2.9 & 3.6 & 2.9 & 1.9 & 1.5 & 3.4 & 1.5 \\
\hline & Incongruent & & 5.4 & 4.0 & 2.7 & 4.2 & 1.7 & 2.1 & 2.5 & 2.9 \\
\hline
\end{tabular}

Note-PM-SOA, stimulus onset asynchrony between first and second stimulus (prime and mask, or prime and cue); MT-SOA, stimulus onset asynchrony between second and third stimulus (mask and target, or cue and target). See text for descriptions of tasks used in the experiments.

PM-SOA and MT-SOA $\left[F(8,64)=3.1, M S_{\mathrm{e}}=56, p<\right.$ $.05]$. RT as a function of MT-SOA is shown in Figures $3 \mathrm{~A}$ and $3 \mathrm{~B}$ for $68 \mathrm{msec}$ and $119 \mathrm{msec}$ PM-SOA, respectively. Figure $3 \mathrm{C}$ shows the priming effect as a function of MT-SOA and PM-SOA. The priming effect was modulated by MT-SOA, as reflected in the significant interaction of congruency and MT-SOA $[F(8,64)=7.2$, $\left.M S_{\mathrm{e}}=153, p=.001\right]$. Post hoc analyses on each level of MT-SOA revealed significant inverse priming effects with MT-SOA of $68 \mathrm{msec}, 136 \mathrm{msec}$, and $340 \mathrm{msec}$ $\left[F(1,8)=18.4, M S_{\mathrm{e}}=1,022, p=.003, F(1,8)=32.4\right.$, $M S_{\mathrm{e}}=284, p<.001$, and $F(1,8)=5.9, M S_{\mathrm{e}}=349, p=$ .041 , respectively (with means of $-32 \mathrm{msec},-23 \mathrm{msec}$, and $-11 \mathrm{msec}$, respectively)]. Visual inspection of the priming effects in Figure $3 \mathrm{C}$ shows that the positive priming effect at 0 -msec MT-SOA and the reversal at 68msec MT-SOA were somewhat larger with 119- than with 68-msec PM-SOA. Although neither the priming effect nor the reversal varied reliably with PM-SOA when tested individually $[F(1,8)=4.7, p=.6$, and $F(1,8)=1.7, p=0.22$, respectively], the interaction of PM-SOA and MT-SOA was significant $[F(1,8)=5.9$, $\left.M S_{\mathrm{e}}=186, p=.4\right]$.

Prime recognition. Overall, prime recognition responses were correct in $71 \%$ of the trials. The participants recognized primes more frequently with long PMSOA $(79.6 \%)$ than with short PM-SOA $(62.5 \%)[F(1,8)=$ $\left.47.3, M S_{\mathrm{e}}=0.017, p<.001\right]$. To assess the relation between prime recognition performance and priming effects on RT, the priming effect-determined for short and long PM-SOA in the condition with 68-msec MT$\mathrm{SOA}$ - was correlated with prime identification performance of each participant for short and long PM-SOA. To estimate the reliability of the measures, priming effects and prime recognition were calculated for each participant for odd and even trials separately. The square of the difference between odd and even trials on these measures was used to estimate the reliability of the measures in each participant. In the 7 participants with the least squared difference on priming effects, the correlation between the priming effect on odd and even trials was significant $[r=$ $.86, p<.001(r=.89, p<.01$ and $r=.85, p<.01$, for 68- and 119-msec PM-SOA, respectively)]. For this subgroup, the prime recognition performance was also reliable $[r=.94, p<.001(r=.82, p<.02$ and $r=.96, p<$ .001 , for 68 - and 119-msec PM-SOA, respectively)]. However, the priming effect was not correlated with prime recognition performance in this subgroup $[r=-.09, p=$ $.77(r=-.24, p=.61$, and $r=.20, p=.66$ for 68 - and 119-msec PM-SOA, respectively; Figure 4)].

\section{Discussion}

Experiment 1 replicated the inhibition of direct motor priming (Eimer, 1999; Eimer \& Schlaghecken, 1998; Klapp \& Hinkley, 2002; Schlaghecken \& Eimer, 2000, 2002; Vorberg, 1998). In addition, Experiment 1 showed that inhibition of direct motor priming depends on MTSOA with a maximum at 68-msec MT-SOA. A second, smaller, phase of the reversal of priming appeared with 340-msec MT-SOA. At longer target delays, the reversal 


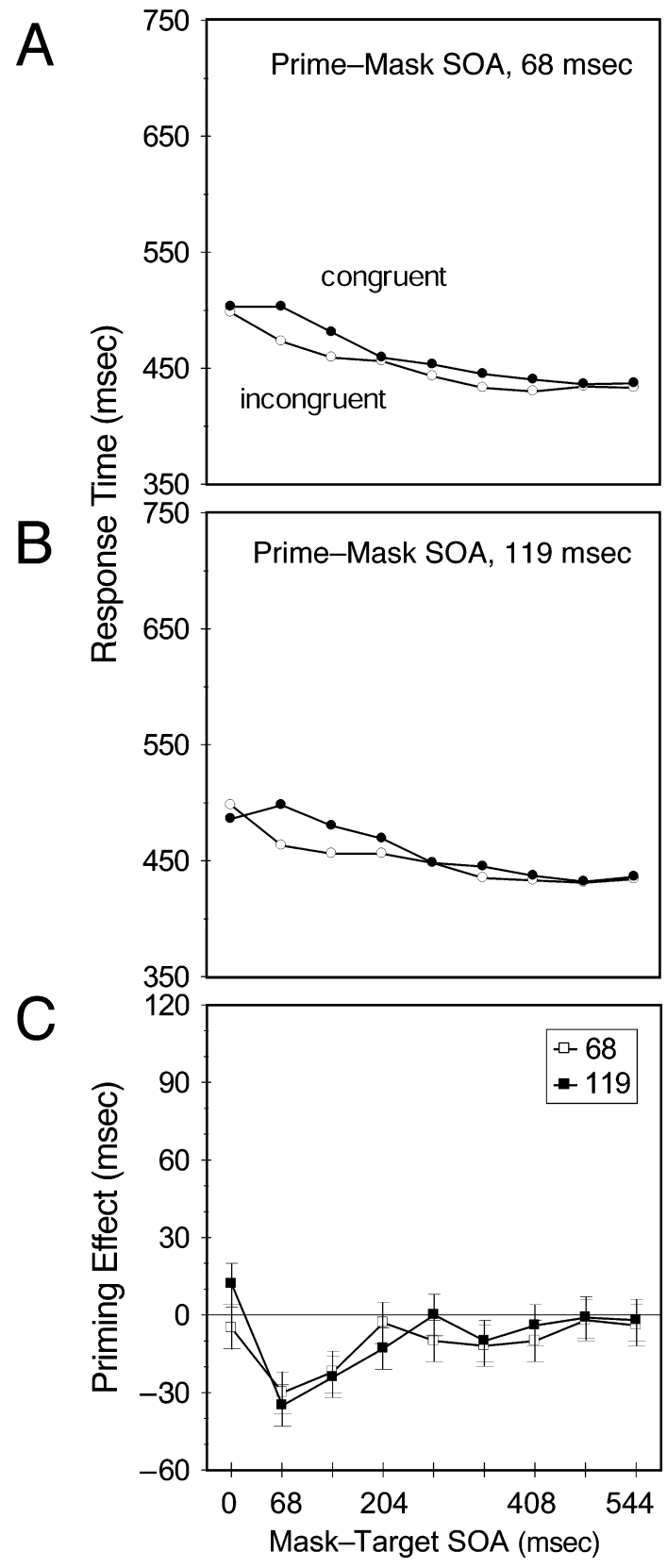

Figure 3. Direct motor priming as a function of prime-mask SOA (PM-SOA) and mask-target SOA (MT-SOA) in Experiment 1 . Effects of congruent and incongruent primes on mean choice RT in conditions with (A) 68-msec PM-SOA and (B) 119msec PM-SOA. (C) Priming function calculated as the difference between RT on incongruent and congruent trials. Error bars indicate confidence intervals of the PM-SOA $\times$ MT-SOA interaction (Loftus \& Masson, 1994).

of direct motor priming decayed to zero. Similar time courses of the inhibition of priming with arrow stimuli have been reported by Vorberg $(1998,2002)$ and Vorberg and Lingnau (in press).

Whereas the absolute size of the inverse priming effect at 68 msec MT-SOA did not depend on PM-SOA, there was a larger relative reversal of the priming effect, with 119-msec as compared with 68-msec PM-SOA when the initial priming effect with 0 -msec MT-SOA was taken into account. This finding suggests that the inhibition of the priming effect depends on the activation that was achieved initially by the primes because the priming effect is typically larger when PM-SOA is increased (e.g., Mattler, 2003; Vorberg et al., 2003). This finding accords with the account of Schlaghecken and Eimer (2002), who proposed a model for the reversal of priming effects. According to this model, each response alternative is controlled by an excitatory and an inhibitory unit in the motor control system. Perceptual input activates the excitatory unit but inhibits the inhibitory unit. Within the motor control system, the excitatory unit of one response alternative activates its inhibitory unit, whereas the inhibitory unit inhibits its excitatory unit only when activation in the inhibitory unit exceeds a threshold. According to the model, the priming effect on behavioral measures is reversed when the perceptual input is removed by the mask because this leads to disinhibition of the inhibitory unit. At this point in time, the inhibitory unit is first activated by the excitatory unit. After a short temporal delay, the inhibitory unit suppresses the activation of the excitatory unit, leading to the reversal of priming effects: A target stimulus that follows a congruent prime is processed more slowly than a target following an incongruent prime. On this background, it seems reasonable that the amount of inhibition depends on the activation of the excitatory unit because this unit is directly activating the inhibitory unit. To the extent that the activation of the excitatory unit is increased with increased PM-SOA, the model therefore predicts the present finding that the reversal of priming also increases with increased PM-SOA.

The size of the maximum of the inverse priming effect at 68 -msec MT-SOA was not correlated with prime identification, which was determined in the last session of the experiment. This finding suggests that inhibition of priming does not depend on the conscious perception of the prime. Furthermore, it shows that the inhibition does not depend on perfect masking. Instead, it replicates findings from Vorberg (2002) that showed inhibition of the priming effect despite above-chance prime visibility. However, these findings disagree with the view that the inhibition of priming effects depends on effective masking of the prime (Klapp \& Hinkley, 2002; see Eimer \& Schlaghecken, 2002). The latter view is consistent with Klapp and Hinkley's finding of inhibition when the mask was presented between the presentation of prime and target stimuli, whereas inhibition was absent when the mask was absent. From the present perspective, the absence of inhibition in the latter condition results from the absence of the mask, which is needed to trigger inhibition, but not from the absence of the masking effect. Therefore, the finding of Klapp and Hinkley does not contradict the present view that prime recognition performance is irrelevant for inhibition of priming. From 


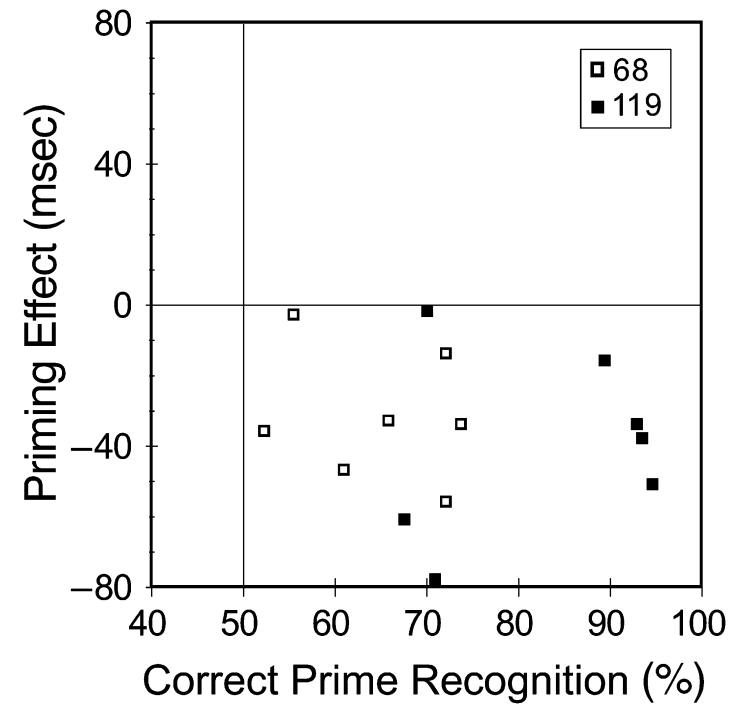

Figure 4. The inhibition of priming effect in direct motor priming as a function of prime recognition performance and PM-SOA in Experiment 1. Each point in the figure reflects the data of a single participant in one of the two conditions of PM-SOA with 68-msec MT-SOA.

the present findings, the hypothesis emerges that the mask in the three-stimulus-paradigm triggers a mechanism that leads to inhibition of the priming effect.

What are the limits of the inhibition of priming effects? In the following three experiments, similar threestimulus paradigms were used to study the fate of priming effects in cue priming tasks. Similar to Experiment 1, the following experiments presented a masking stimulus after the prime and prior to target presentation. If the mask triggers a mechanism that results in the inhibition of the priming effects, reversals of priming should be observed in nonmotor priming similar to those found with direct motor priming in Experiment 1.

\section{EXPERIMENT 2 Priming of Attention}

In direct motor priming experiments, such as Experiment 1 , the prime shares attributes with the target stimulus and can therefore be directly associated to motor responses. In the following three experiments, however, the prime shares attributes with the mask, which was never directly associated to a motor response. Instead, the mask served as a cue providing obligatory information to perform the task. In Experiment 2, the cue provided information about the likely stimulus modality. Cuing of stimulus information is a common technique to direct the participant's attention to events of interest in the environment (e.g., see Pashler, 1998). Many everyday situations require attention to be coordinated across sensory modalities. Spence and Driver (1997) effectively used the cuing technique and confirmed previous reports that RT is longer in trials with targets presented in an unexpected modality than in trials with targets in the ex- pected stimulus modality. These findings show that we can indeed selectively attend to the auditory or the visual modality. Beyond these effects of clearly visible cues on the direction of attention, a prior study showed that masked stimuli too can affect attending to the auditory or visual modality (Mattler, 2003). Experiment 2 was an attempt to replicate this finding and study the time course of nonmotor priming as a function of the time interval between mask and target stimulus.

It is important to note that cue priming effects have to be distinguished from direct motor priming effects. To this end, participants cannot be allowed to simply combine the cue with the target stimulus and respond to the resulting complex stimulus event. Otherwise, priming effects in cuing paradigms might result from a complex stimulus-response mapping in which participants associate certain combinations of cue and target stimuli to specific motor responses. To this end, participants were instructed in all of the following experiments to process the cue prior to the target stimulus. In addition, they were asked after each choice RT session how they had processed cues.

\section{Method}

Participants. Eight students from the University of Braunschweig ( 7 women, 1 man) from 19 to 38 years of age $(M=25.8$ years) participated in the experiment. Six reported being right-handed and all had normal or corrected-to-normal vision. Each participant took part in six 1-h sessions, receiving course credit for participation.

Task. Participants responded to the high- (low-) pitch tone, and to the red (green) color bars by pressing the left (right) ALT key on the keyboard with the left (right) index finger. To know which stimulus modality to attend to, they had to use the shape of the mask: Diamond-shaped mask stimuli indicated that participants should respond to the tone, whereas square stimuli indicated that participants should respond to the color.

Stimuli. Experiment 2 differed from Experiment 1 in that no neutral mask was used. Instead, the mask was informative because participants had to use the mask as a cue. Prime and mask stimuli were identical to the prime and target stimuli used in Experiment 1, respectively (Figure 1). Primes were congruent with the mask in half of the trials, with congruency varying randomly between trials. The target was presented for $102 \mathrm{msec}$ about $1.8^{\circ}$ of visual angle above and below fixation (Figure 5). On half of the trials, a visual target was presented: Two identical color bars (green or red) were shown above and below fixation. Color bars were about $2.1^{\circ}$ and $.3^{\circ}$ in width and height, respectively. On the other half of the trials, the target was a high- or low-pitch tone $(1500$ vs. $300 \mathrm{~Hz})$ that was presented by a loudspeaker located $12^{\circ}$ of visual angle below the fixation point. The MT-SOA varied from 68 to $544 \mathrm{msec}$. To motivate the participants to use the mask as a cue, the stimulus display was equivocal in the half of the trials in which one of the visual stimuli was accompanied by one of the auditory stimuli. Thus, on $12.5 \%$ of the trials, a visual (auditory) target was accompanied by an auditory (visual) distractor that was associated to the same response as the visual target (compatible distractor), and on $12.5 \%$ of the trials the auditory (visual) distractor was associated to the opposite response as the visual (auditory) target (incompatible distractor). On the remaining half of the trials, targets were presented without a distractor. Thus, at least in the $25 \%$ of the trials with an incompatible distractor, the participants had to use the mask as a cue to know what to do. An auditory stimulus of $1000 \mathrm{~Hz}$ and $100-\mathrm{msec}$ duration served as error feedback.

Procedure. Experiment 2 differed in the following points from Experiment 1 . The participants were instructed to focus the fixation 


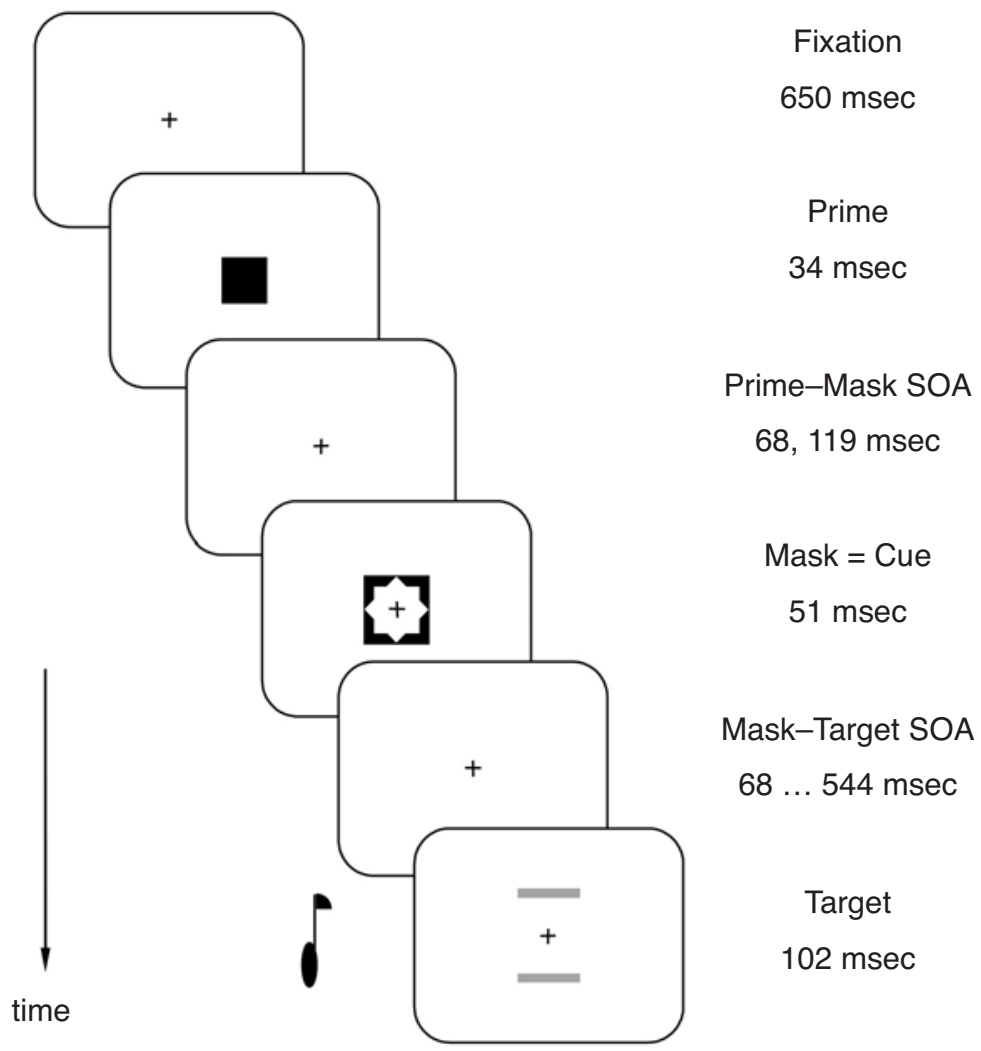

Figure 5. Schematic diagram of stimulus events in Experiments 2-4. In the choice RT task, participants used the mask as a cue. The stimulus presented after the mask served as the target. Priming effects were assessed by the effects of prime-mask congruency on RT. In the prime recognition task in Experiment 3, participants reported the prime. The time course of priming was assessed by varying SOA between prime and neutral mask and between mask and target randomly from trial to trial. Note that the bars in the last frame were either green or red. Experiment 2 used the color bars and tones as targets in the choice RT task. Experiment 3 used no color bars at all, but presented sounds via headphones as targets in the choice RT task.

stimulus, to use the mask as a cue to shift their attention to the indicated stimulus modality, and to respond as quickly as possible, without making errors. They were instructed to process the cue prior to the target stimulus. The stimulus sequence is given in Figure 5. Note that the timing of events was identical in Experiments 1 and 2 (compare Figures 2 and 5).

Design. A practice session was followed by five sessions with the choice RT task, comprising 80 replications of each of the 32 conditions resulting from the combination of the independent variable PM-SOA (two levels), MT-SOA (eight levels), and prime--mask congruency (two levels). In addition, the independent variable distractor presence was varied: Half of trials were with and half without a distractor in the irrelevant modality.

\section{Results}

After each choice RT session, participants were given questions concerning their behavior during the session. All participants reported having used masks as cues to concentrate on the indicated stimulus modality or to ignore the alternative stimulus modality. Participants were asked, "How well could you prepare the indicated stim- ulus modality prior to the target stimulus?" (using a 5point scale, very badly to very well). In 36 out of the total of 40 choice RT sessions, participants could prepare "well" or "very well" for the indicated stimulus modality prior to target presentation.

Errors. Errors occurred on $2.3 \%$ of the trials, but no independent variable had a significant effect (Table 1).

RT. Congruency affected RT significantly with faster responses on congruent trials $(393 \mathrm{msec})$ than on incongruent trials (400 msec) $\left[F(1,7)=8.3, M S_{\mathrm{e}}=943, p<\right.$ $.05]$. RT decreased with target delay, as reflected in the significant effect of MT-SOA $\left[F(7,49)=118.4, M S_{\mathrm{e}}=\right.$ $505, p<.001]$. This decrease in RT was modulated by PM-SOA, as reflected in the significant interaction of PM-SOA and MT-SOA $\left[F(7,49)=3.4, M S_{\mathrm{e}}=124, p<\right.$ $.05]$. Figures $6 \mathrm{~A}$ and $6 \mathrm{~B}$ show RT as a function of MTSOA for 68- and 119-msec PM-SOA. The figures show faster responses with 119- versus 68-msec PM-SOA for short MT-SOA (68 and $136 \mathrm{msec}$ ), but similar RTs for 
longer MT-SOA. Figure 6C shows the priming effect as a function of MT-SOA and PM-SOA. The priming effect increased with PM-SOA, as reflected in the significant interaction of congruency and PM-SOA $[F(1,7)=7.4$, $\left.M S_{\mathrm{e}}=259, p<.05\right]$. Priming decreased, however, with target delay, as reflected by the significant interaction of congruency and MT-SOA $\left[F(7,49)=4.5, M S_{\mathrm{e}}=230\right.$, $p<.05]$. The only effect of distractor consisted in the significant interaction of distractor and MT-SOA $\left[F(7,49)=5.5, M S_{\mathrm{e}}=125, p<.01\right]$. RT was facilitated by the presence of distractors on trials with MT-SOA below $400 \mathrm{msec}$. Most importantly, priming did not depend on the presence of a distractor.

\section{Discussion}

Experiment 2 showed priming in a cuing paradigm and replicated priming of attention to visual or auditory stimulus modalities (Mattler, 2003). Furthermore, the effect of PM-SOA replicates previous findings of the time course of priming of attention: Priming effects increased with the interval between prime and mask (Mattler, 2003). Note that priming of attention cannot be accounted for by processing along a visuomotor pathway leading immediately to action, because the cue in Experiment 2 did not convey information about the overt motor response (e.g., Leuthold \& Kopp, 1998; Neumann \& Klotz, 1994; Vorberg et al., 2003). Instead, results suggest that primes modulated the guidance of attention to different stimulus modalities. Beyond this, Experiment 2 showed that priming effects decreased with the delay of the target stimulus after the cue to zero.

In contrast to the finding of an inhibition of priming effects with 68-msec MT-SOA in Experiment 1, priming effects did not show a comparable inhibition in Experiment 2. This result of Experiment 2 is consistent with the view that the inhibition of priming effects in direct motor priming is a phenomenon that is not found in the same way with nonmotor priming (e.g., Eimer, 1999; Eimer \& Schlaghecken, 1998). However, the effects of priming of attention in Experiment 2 were rather small, similar to the priming effects found in the previous study (Mattler, 2003). These small priming effects might not have triggered the suppression mechanism, which might be responsible for the absence of the inhibition of priming effects. For this reason, Experiment 3 used a different version of nonmotor priming that has previously led to larger priming effects (Mattler, 2003).

Do the present priming effects result from priming in a complex stimulus-response assignment? For instance, participants could have mapped the complex stimulus combination square-plus-green-bars to a right-hand response, and the complex stimulus square-plus-red-bars to a left-hand response. To avoid any strategy like this, participants have been systematically motivated to process the mask as a cue prior to the following target stimulus in this and all following experiments. Reports in interviews after each session revealed that participants followed instructions and effectively used a sequential
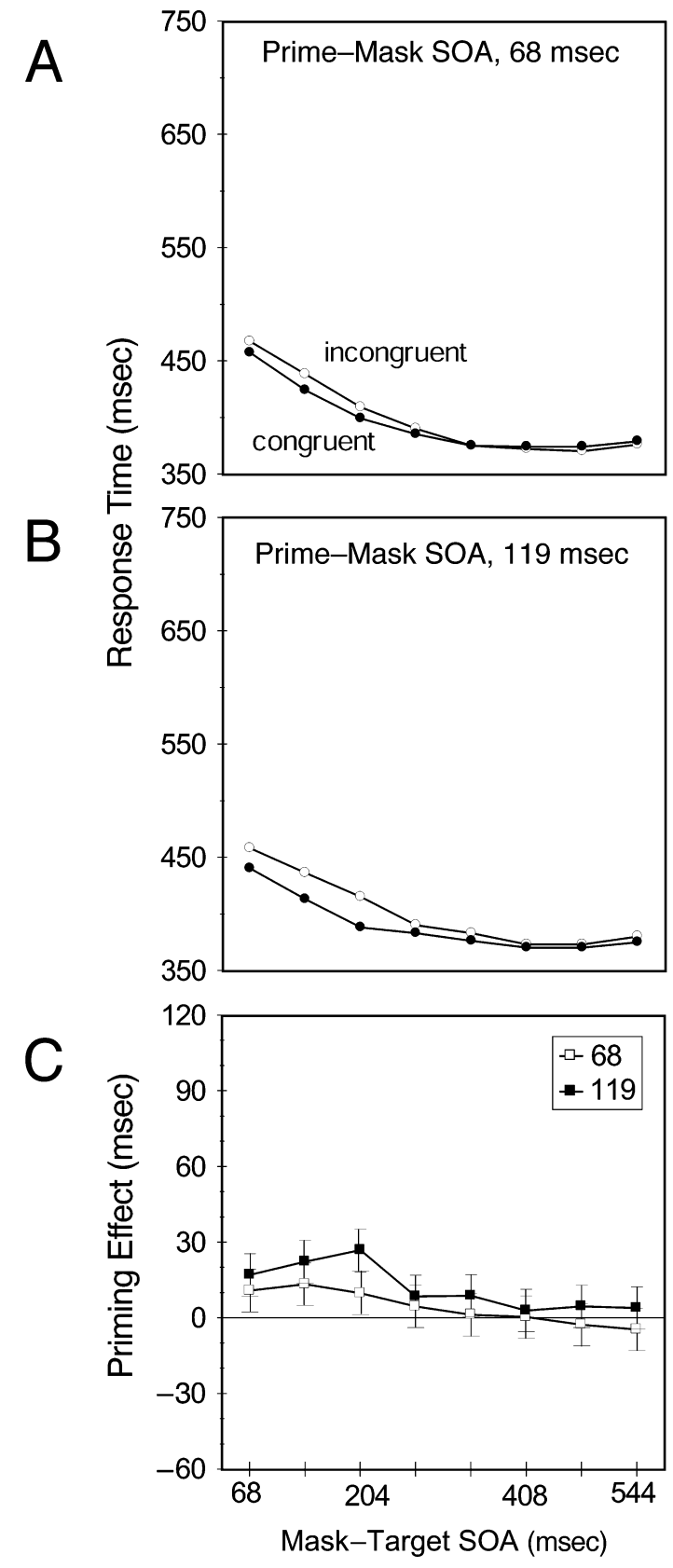

Figure 6. Priming of attention as a function of PM-SOA and MT-SOA in Experiment 2: Effects of congruent and incongruent primes on mean choice $R T$ in conditions with (A) 68-msec PMSOA and (B) 119-msec PM-SOA. (C) Priming function calculated as the difference between $\mathrm{RT}$ on incongruent and congruent trials. Error bars indicate confidence intervals of the PM-SOA $\times$ MT-SOA interaction.

strategy in which the mask was processed as a cue prior to the target. Furthermore, participants occasionally reported that the task became very difficult when the instructed strategy was not used and the response was instead made on the basis of the memory from the sequence of stimuli. This task difficulty was reflected in the data of an unpub- 
lished experiment in which participants were not properly instructed. These participants responded rather slowly, with largely varying RTs and high error rates. In fact, the instruction used in the present experiments was one consequence of these unpublished findings. Therefore, the self-reports and the behavioral data of the present study suggest that the present priming effects do not result from complex stimulus-response assignments.

\section{EXPERIMENT 3 Priming of Cognitive Control Operations}

Instead of priming of attention, Experiment 3 studied priming of cognitive control operations (see Mattler, 2003). Research on cognitive control assumes that we can adopt a particular configuration of our cognitive system to perform a given task, like making coffee or comprehending a spoken sentence (Allport, Styles, \& Hsieh, 1994; Rogers \& Monsell, 1995). According to this, we can prepare to perform a task that involves linking and configuring processing modules that are responsible for different aspects of the task, like stimulus processing, response selection, or response execution (e.g., Monsell, 1996). In the prior study, it was found that even masked primes can affect cognitive control operations involved in task-set selection and activation. Experiment 3 attempted to replicate this finding and to study the time course of priming effects as a function of mask-target SOA. The experiment used cues that specified the task to be performed on multidimensional auditory stimuli. Unlike in Experiment 2, the stimulus modality remained constant in Experiment 3, and participants responded to identical stimuli according to different stimulusresponse mappings in different trials. Therefore, instead of specifying the stimulus modality or any response parameter, the cue in Experiment 3 specified the cognitive operation necessary for performing the task. Because this paradigm has been proven to result in larger priming effects than those found in priming of attention, Experiment 3 was considered to provide a better test for the hypothesis that nonmotor cue priming effects reverse when target presentation is delayed after the mask.

\section{Method}

Participants. Seven new students from the University of Braunschweig ( 5 women, 2 men) from 20 to 32 years of age $(M=$ 25.3 years) participated in the experiment. All reported being righthanded and had normal or corrected-to-normal vision. Each participant took part in seven 1-h sessions, receiving course credit for participation.

Stimuli. Prime and mask stimuli were identical to those of Experiment 2 (Figure 1). After the mask, a MIDI sound was presented over headphones. The sound was that of either a piano or a marimba with high or low pitch, which differed by seven notes. No visual stimulus accompanied the presentation of the sounds. Except for the target stimulus, the sequence of stimuli and the procedure were identical to those of Experiment 2 (Figure 5). However, error feedback was given by the German word Fehler ("error"), presented for $1 \mathrm{sec}$.

Tasks. As in Experiment 1, two tasks were employed. (1) The participants indicated either the pitch (low vs. high) or the timbre (piano vs. marimba) of the sound by pressing the left or right ALT key on the keyboard with their left or right index finger. The task in effect was indicated by the shape of the mask: Diamond-shaped mask stimuli indicated the pitch task, and squares indicated the timbre task. (2) The entire last session was used to measure prime recognition in the same way as in Experiment 1.

Design and Procedure. Experiment 3 differed from Experiment 2 because the mask served as a cue that indicated the task to be performed on the multidimensional stimulus, and the cue could not be used for preparation of stimulus modality or any motor preparation.

\section{Results}

In interviews after choice RT sessions, the participants reported having used cues to concentrate on the indicated stimulus dimension. Only one of them reported having thought of stimulus-response associations in addition to the cued stimulus dimension in the first session. All of them processed cues prior to the target. They reported that in 31 out of 35 experimental sessions, they could prepare at least "well" for the indicated stimulus dimension prior to the target stimulus.

Errors. Errors occurred on 3.1\% of the trials. Error rates were not significantly affected by any experimental variable (Table 1 ).

RT. Congruency affected RT with means of 593 and $609 \mathrm{msec}$ for congruent and incongruent trials, respectively $\left[F(1,6)=10.0, M S_{\mathrm{e}}=1,454, p<.05\right]$. RT decreased with target delay, as shown in the effect of MTSOA $\left[F(7,42)=68.8, M S_{\mathrm{e}}=1,494, p<.001\right.$; see Figures 7A and 7B]. The priming effect increased with PM-SOA (Figure 7C), as reflected by the significant interaction of PM-SOA and congruency $[F(1,6)=21.3$, $\left.M S_{\mathrm{e}}=370, p<.01\right]$. Furthermore, the priming effect decreased with target delay, although the interaction of congruency and MT-SOA just failed to reach significance $\left[F(7,42)=3.3, M S_{\mathrm{e}}=811, p=.05\right]$.

Prime recognition. Overall, prime recognition responses were correct in $69.3 \%$ of the trials. There was no effect of PM-SOA. To assess the relation between prime recognition performance and priming effects on RT, the priming effect of each participant - determined for short and long PM-SOA across all other conditionswas correlated with their prime recognition performance for short and long PM-SOA. As in Experiment 1, the reliability of the measures was estimated in terms of the squared difference between measures on odd and even trials. In the 6 participants with the least squared difference on measures of the priming effect, the correlation between the priming effect on odd and even trials was significant $[r=.77, p=.002(r=.75, p<.05$, and $r=$ $.58, p=.11$, for 68 - and 119-msec PM-SOA, respectively)]. For this subgroup, measures of prime recognition performance were also reliable $[r=.91, p<.001$ $(r=.92, p<.01$, and $r=.94, p<.01$, for 68 - and 119 msec PM-SOA, respectively)]. For this subgroup, the priming effect was not correlated with prime recognition performance $[r=.07, p=.82(r=.50, p=.31$, and $r=$ $-.33, p=.52$ for 68 - and 119-msec PM-SOA, respectively; Figure 8)]. 

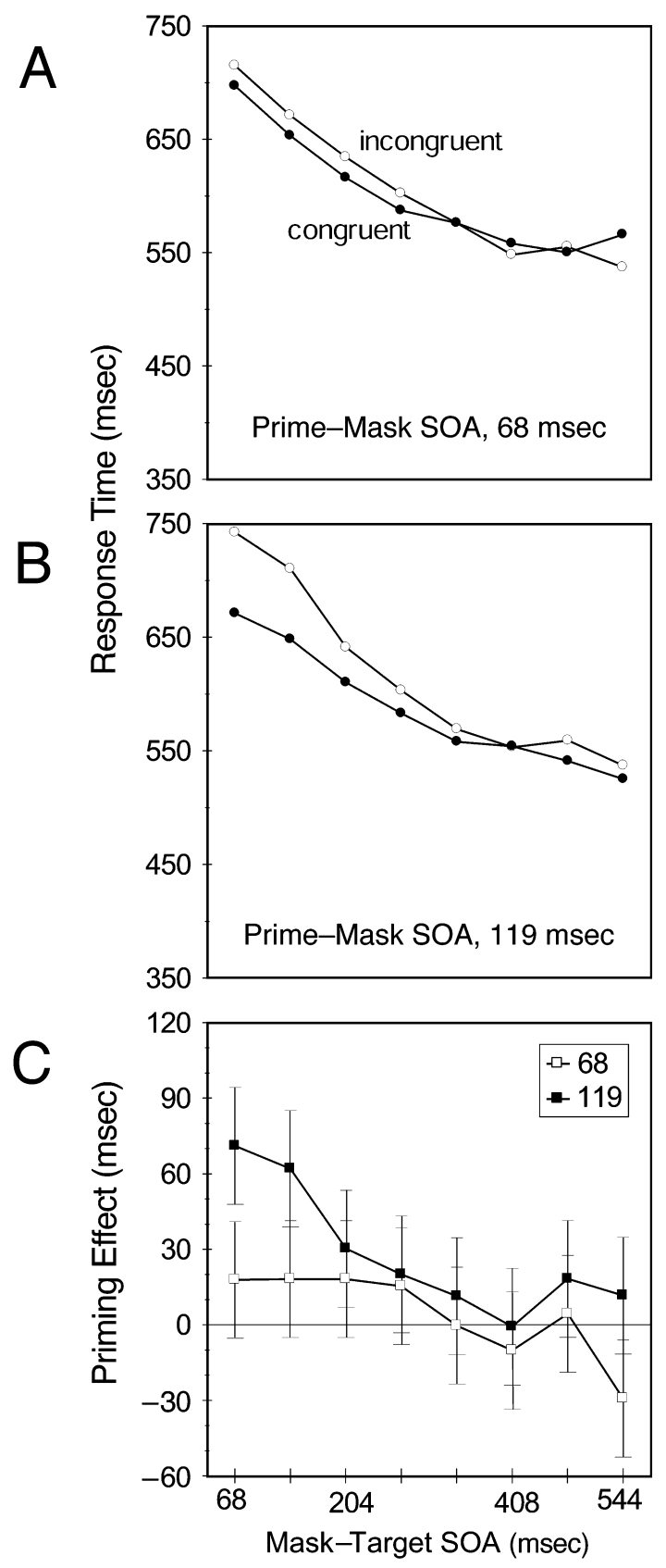

Figure 7. Priming of control operations as a function of PMSOA and MT-SOA in Experiment 3: Effects of congruent and incongruent primes on mean choice $R T$ in conditions with (A) 68msec PM-SOA and (B) 119-msec PM-SOA. (C) Priming function calculated as the difference between $R T$ on incongruent and congruent trials. Error bars indicate confidence intervals of the PMSOA $\times$ MT-SOA interaction.

\section{Discussion}

Experiment 3 replicated priming of nonmotor operations, which increased with PM-SOA (Mattler, 2003). Furthermore, priming of cognitive operations revealed larger effects than priming of attention in Experiment 2, replicating a similar pattern of results in a prior study
(Mattler, 2003). Priming effects did not correlate with prime recognition performance in Experiment 3. This finding is in line with those of Mattler, suggesting that cue priming does not depend on conscious awareness of the primes.

In contrast to Experiment 1, Experiment 3 showed no comparable inhibition of priming effects. Instead, consistent with the results of Experiment 2, priming effects decreased, with target delay approaching zero levels of priming. Thus, together with Experiment 2, these findings suggest that nonmotor cue priming is not affected by active inhibition of priming effects in the same way as with direct motor priming. Instead, nonmotor cue priming effects seem to decay passively. However, a directly comparable experiment on motor priming is required. To this end, Experiment 4 was conducted with an indirect motor priming task to see whether the reversal of priming effects requires some kind of motor priming.

\section{EXPERIMENT 4 Priming of Motor Precuing}

In direct motor priming experiments, the prime shares attributes with the target stimulus, which allows a direct association of primes to motor responses. In contrast, in Experiment 4, on indirect motor priming, the mask did not specify an overt response directly, but provided partial information of the response to be given. Therefore, primes cannot be associated directly to motor responses. More specifically, the mask served as a cue indicating the responding hand without fully specifying a particular overt response. Experiment 4 was conducted to see whether indirect motor priming effects are inhibited after a certain target delay. From the findings of the previous two experiments, however, it was expected that indirect motor priming effects simply decay to zero without signs of inhibition of priming.

\section{Method}

Participants. Six new students from the University of Braunschweig (5 women) from 19 to 33 years of age ( $M=22.3$ years) participated in the experiment. All reported being right-handed and had normal or corrected-to-normal vision. Each participant took part in five 1-h sessions, receiving course credit for participation.

Task. Participants had to respond to red bars with their middle finger and to green bars with their index finger. A shape cue informed them which hand to use: A square cued a right-hand response, and a diamond cued a left-hand response.

Stimuli, Procedure, and Design. Prime and mask stimuli were the same as in the previous experiments, and the color bars used in Experiment 2 served as target stimuli. In contrast to the previous experiments, four response alternatives were used. Responses were given by pressing the appropriate response button with the middle or index finger of the left or right hand. Only the RT task in which the mask served as a cue for a speeded choice response to the color bars was studied.

\section{Results}

All participants reported having used masks as cues to prepare the indicated response hand. In 22 out of the total of 24 choice RT sessions, the participants could 


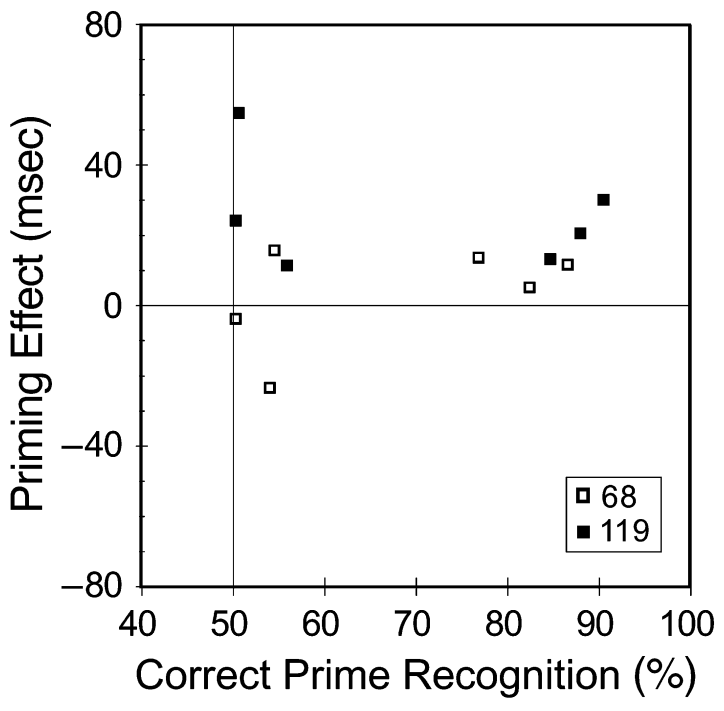

Figure 8. Priming of control operations as a function of prime recognition performance and PM-SOA in Experiment 3. Each point in the graph reflects the data of a single participant in one of the two conditions of PM-SOA averaged across MT-SOA.

prepare the hand "well" or "very well" prior to the target stimulus.

Errors. Errors occurred on $2.6 \%$ of the trials, and experimental variables had no significant effect (see means in Table 1).

RT. Primes influenced motor cuing effects, as shown by the effect of congruency, with means of 526 and $549 \mathrm{msec}$ for congruent and incongruent trials, respectively $\left[F(1,5)=27.1, M S_{\mathrm{e}}=960, p<.01\right]$. Figures 9A and $9 \mathrm{~B}$ show that mean RTs decreased with MT-SOA $\left[F(7,35)=62.3, M S_{\mathrm{e}}=1,301, p<.001\right]$. Priming effects are shown in Figure 9C. Priming effects decreased with MT-SOA, as shown by the significant interaction of congruency and MT-SOA $\left[F(7,35)=12.3, M S_{\mathrm{e}}=316\right.$, $p=.001]$. In addition, the priming effect depended on PM-SOA, as revealed by the significant interaction of congruency and PM-SOA $\left[F(1,5)=64.0, M S_{\mathrm{e}}=115\right.$, $p<.001]$. Finally, the interaction of congruency, PMSOA, and MT-SOA was significant $[F(7,35)=3.6$, $\left.M S_{\mathrm{e}}=191, p<.05\right]$.

\section{Discussion}

Experiment 4 replicated previous findings, with this paradigm showing priming in a motor cuing paradigm and increasing indirect motor priming effects with increasing PM-SOA (Mattler, 2003). Beyond this, priming effects decreased with the delay of the target stimulus to levels of zero. Most importantly, indirect motor priming effects did not reverse in the same way as direct motor priming effects reversed in Experiment 1. Instead, the time course of indirect motor priming replicated the time course of nonmotor priming in Experiments 2 and 3. Thus, partial priming of motor responses is not a sufficient condition for the reversal of priming effects.
Comparing experiments. In the latter three experiments, prime and mask stimuli, as well as the stimulus intervals (PM-SOA and MT-SOA), were identical. Therefore, the priming effects of all three experiments could be compared. The priming effect was generally reduced with priming of attention in Experiment 2, as reflected in the main effect of the factor experiment, which just failed to reach significance $\left[F(2,18)=3.5, M S_{\mathrm{e}}=1,875, p=\right.$ $.052]$. The effect of PM-SOA was smaller in priming of attention, as reflected in the significant interaction of PM-SOA and experiment $\left[F(2,18)=6.4, M S_{\mathrm{e}}=419\right.$, $p<.01]$. Furthermore, there was a trend toward different effects of MT-SOA on the priming effect in the three experiments: The interaction of MT-SOA and experiment just failed to reach significance $[F(14,126)=2.0$, $\left.M S_{\mathrm{e}}=806, p=.06\right]$. This effect results because priming effects reached zero levels after a target delay of about $300 \mathrm{msec}$ despite large differences in the initial size of the priming effect at short MT-SOAs (Figures 6, 7 , and 9).

The comparison of experiments revealed that priming effects decreased faster when the initial priming effects were high. On the one hand, this finding suggests that the fate of indirect motor priming, priming of attention, and priming of cognitive control operations is different. For instance, it could be argued that the faster decrease in motor priming indicates active suppression of priming (e.g., Band \& van Boxtel, 1999; Eimer, 1999; Eimer \& Schlaghecken, 1998), whereas nonmotor priming effects are suppressed to a minor degree or even decay passively. This interpretation is interesting because it suggests that the suppression mechanism is related to motor activation (e.g., Ridderinkhof, 2002). However, this view is questionable due to the absence of direct evidence in terms of a reliable inhibition of priming effects. Alternatively, differences between the rate of decreasing priming effects might result from a nonlinear (e.g., exponential) passive decay. According to this view, high levels of priming decay rapidly, whereas low levels of priming decay slowly, leading to the observed interaction. This view is consistent with a mathematical model of the priming effect proposed by Vorberg et al. (2003), which assumes exponential increase and decay of priming effects.

Visual inspection of the time courses of the three experiments suggests that there is a an inverse priming effect in the 68-msec PM-SOA condition, with 544-msec MT-SOA in each of the three cue priming experiments (Figures 6, 7, and 9). A $t$ test of the data in this condition averaged across all three experiments was significant $[t(20)=-2.3, p=.017$ (single sided) $]$. On the one hand, this effect has to be taken seriously because the same effect is found in each of the three experiments at the last level of MT-SOA with PM-SOA of $68 \mathrm{msec}$. On the other hand, however, this late effect has to be distinguished from the early reversal of priming shown in Experiment 1 because the early effect occurred with $68-\mathrm{msec}$ MT-SOA, whereas the late effect occurred with 544-msec MT-SOA. Whereas the early effect corresponds to previ- 

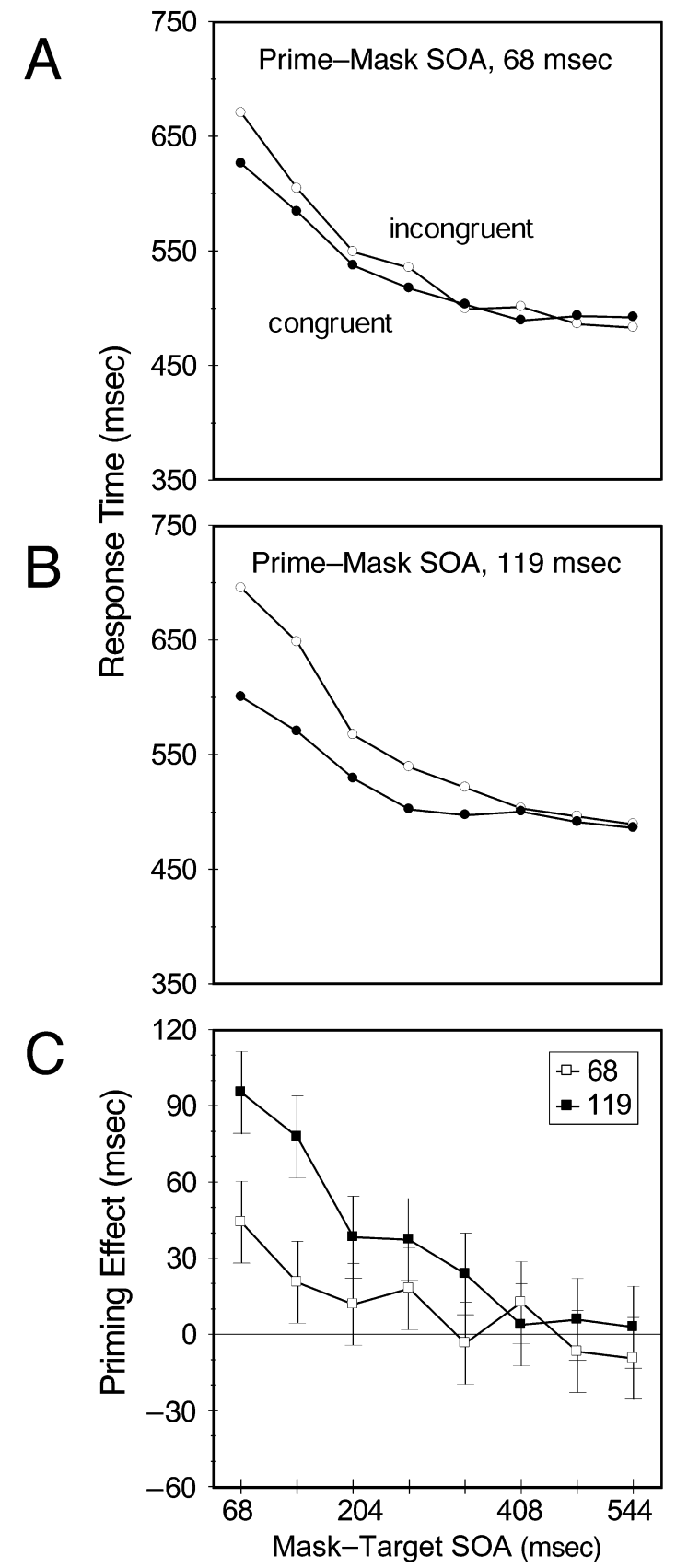

Figure 9. Priming of motor cuing as a function of PM-SOA and MT-SOA in Experiment 4: Effects of congruent and incongruent primes on mean choice $R T$ in conditions with (A) 68-msec PMSOA and (B) 119-msec PM-SOA. (C) Priming function calculated as the difference between RT on incongruent and congruent trials. Error bars indicate confidence intervals of the PM-SOA $\times$ MT-SOA interaction.

ous reports of reversed priming effects (e.g., Vorberg, 1998, 2002; Vorberg \& Lingnau, in press), the late effect calls for further research to determine the reliability and the boundary conditions of this late reversal of priming effects. At the present time, it can be concluded that the early reversal of priming effects, shown in direct motor priming, was not found in the cue priming paradigm. Instead, cue priming effects decayed within about $300 \mathrm{msec}$. Beyond this, however, there was evidence for a late reversal of priming effects in conditions with indirect priming and 68-msec PM-SOA.

\section{GENERAL DISCUSSION}

The study examined the three-stimulus paradigm to see whether cue priming effects reverse - as direct motor priming effects do-when the temporal interval between the second and the third stimulus is appropriate. Experiment 1 demonstrated the time course of inhibition of direct motor priming. Three subsequent cue priming experiments replicated previous reports of priming effects on mental operations. However, nonmotor priming effects as well as indirect motor priming effects decayed to zero when the target was presented about $300 \mathrm{msec}$ after cue onset. Thus, cue priming did not show a reversal comparable to that found with direct motor priming across a wide range of MT-SOAs. This result shows that the three-stimulus paradigm and a specific interval between the cue and the target are not sufficient conditions for inverse priming.

\section{Comparing Inhibition and Decay of Priming Effects}

A three-stimulus paradigm was used in all experiments of the present study: The prime was followed by the mask, which was then followed by the target stimulus. This paradigm produced inverse priming effects in previous studies on direct motor priming (e.g., Eimer, 1999; Eimer \& Schlaghecken, 1998; Klapp \& Hinkley, 2002; Vorberg, 1998), but the reversal was absent in cue priming experiments (Mattler, 2003). In a first attempt to examine these different outcomes in the three-stimulus paradigm, cue priming effects were studied at various MT SOAs because previous work showed that the interval between the second and the third stimulus is crucial for the reversal of direct motor priming effects. Experiment 1 demonstrated the time course of inverse priming effects. All experiments on cue priming, however, did not show a comparable reversal of priming effects. Therefore, the absence of inverse cue priming effects in previous experiments cannot be reduced to inappropriate temporal variables.

As mentioned in the introduction, two other factors are potentially relevant to account for the reversal of direct motor priming experiments and its absence in cue priming experiments. First, in the direct motor priming of Experiment 1, square and diamond shapes were associated to a specific motor response. In cue priming, however, these shapes were not directly associated to a motor response. Given the evidence for direct motor activation of primes in a comparable paradigm (e.g., Vorberg et al., 2003), it can be assumed that the primes in Experiment 1 activate motor responses. In contrast, the primes in the other experiments could not activate motor responses because the shapes were not associated to a specific 
motor response. Therefore, early inhibition of priming might depend on the direct impact of priming effects on the motor system. This view is consistent with current models on the effect of irrelevant information (e.g., Band \& van Boxtel, 1999; Ridderinkhof, 2002), which assume that irrelevant information affects response activation, which is held in check through inhibitory control mechanisms. Ridderinkhof proposed a more detailed model of response inhibition. According to this model, an instance of selective suppression of response activation is located relatively late in the chain of information processing. Suppression is assumed to affect primarily those response activations that follow from a direct impact of irrelevant information onto the motor system. From this view, it would be predicted that inhibition of priming depends on the direct impact of primes on specific motor responses. In other words, direct motor activation might be required to trigger the mechanism that leads to early inhibition of priming effects.

A second factor could be crucial for the emergence of early inhibition of priming. Experiments on direct motor priming use a neutral mask. In cue priming experiments, the mask is used as a cue. The neutral mask might be recognized as a task-irrelevant stimulus and trigger inhibition of the effects of the previous stimulus. On the other hand, when the mask has to be used as a cue, the processing of the similar prime might not be disrupted and inhibition might not be triggered. Therefore, the presence of a neutral mask might be necessary to trigger early inhibition. A similar argument was raised by Law, Pratt, and Abrams (1995) regarding the effect of a neutral stimulus between the cue and a target in an inhibition-ofreturn paradigm. These authors argued that it was crucial to have a neutral stimulus between the first and the third stimulus to trigger inhibition of return. Future research will have to determine whether the reversal of priming effects is specific to motor processing or whether the mask has to be neutral to trigger inverse priming.

\section{Decay of Priming Effects}

The time course of the decay resembles previous reports of decay effects in the Simon task (Eimer, Hommel, \& Prinz, 1995; Hommel, 1997). For instance, Hommel's RT distribution analyses revealed that irrelevant spatial information decays during the first $600 \mathrm{msec}$ after stimulus onset. This time course of decay corresponds widely to the measures of the present experiment. Note that a comparison of the present data with those of Hommel has to take into account that RT was measured here as the time interval between target onset and the response. To compare the present findings with those of Hommel requires adding PM-SOA and MT-SOA to RT, showing that the priming effect decayed to zero during the $800 \mathrm{msec}$ after prime onset. The somewhat slower decay in the present experiments might also result from procedural and methodological differences: The present design examined the decay of task-relevant shape features using SOA variations, whereas Hommel examined the decay of irrelevant spatial information by means of RT distribution analyses. Nonetheless, similar time courses of decay of priming effects and decay of the Simon effect suggest that similar mechanisms operate in both paradigms. Regarding the location of the decay of the priming effects, the present experiments are at odds with a location at response levels because the same time course of decay was found, although primes were not directly related to motor responses. Thus, to the degree that the same mechanisms are responsible for decay of priming effects and for decay of the Simon effect, the present results suggest that the decay of the Simon effect is also located somewhere in the processing chain before the response level (see Hommel, 1997).

\section{The Locus of Cue Priming Effects}

In the present cue priming experiments, as well as in those of Mattler (2003), the cue was perceptually similar to the prime. Therefore, priming effects could result from early perceptual interactions between the prime and the cue. To measure this perceptual interaction, the metacontrast masking function (Breitmeyer, 1984; Francis, 1997) was examined in Mattler's experiments. Comparing the metacontrast masking functions with the time course of the priming effects revealed substantial differences: The interaction of prime and mask at perceptual levels resulted in improved prime recognition performance at short and at long prime-mask SOA, but poorer prime recognition performance with intermediate SOA. The cue priming effects, however, increased in a monotonic fashion with SOA. Consistent with these findings, Experiment 3 showed that prime recognition performance did not correlate with the priming effect. These findings suggest that the priming effects do not result from interactions at perceptual levels of processing.

Another finding of the present experiments, as well as those of Mattler (2003), disagrees with a perceptual source of the priming effects. If we assume that priming effects result from perceptual interactions, we would have to expect the same amount of priming regardless of the meaning of the cue. However, priming effects had different sizes depending on the meaning of the cue in the present as well as in the previous experiments, although prime and cue stimuli were physically identical in all experiments: small priming effects with priming of attention, larger effects with priming of control operations, and even larger effects with priming of motor cuing. These differences question the view that priming effects result from a single source in each of these experiments.

Finally, research on direct motor priming provides behavioral (Vorberg et al., 2003) as well as electrophysiological data (Dehaene et al., 1998; Eimer \& Schlaghecken, 1998; Leuthold \& Kopp, 1998) suggesting that primes can activate responses in the motor system. For instance, inconsistent primes induce an activation of corresponding motor cortical areas and lead to an increase in choice error rates up to $60 \%$ (Vorberg et al., 2003). These priming effects suggest that incongruent primes 
not only hinder the perception of the following stimulus but also activate their associated response. For these reasons, it seems unlikely that priming effects can be reduced entirely to prime-mask interactions at early perceptual levels.

Therefore, at least part of the priming effect has to be located at levels of processing like central control processes, or processes that are subject to control. Because primes can activate motor responses in direct motor priming tasks, it seems plausible that primes can activate internal responses in cue priming tasks as well. Thus, primes might affect the internal response to switch attention from the visual to the auditory modality, when cues that are similar to the prime are used to switch stimulus modality. Therefore, cue priming effects should be regarded as priming of mental operations (see Mattler, 2003).

\section{Comparable Findings in Cue Priming}

The present finding of similar decay in priming of attention, priming of control operations, and indirect motor priming provides further support for the view that motor and nonmotor priming are governed by similar mechanisms. This finding extends those of Mattler (2003), who varied the interval between prime and mask to study the time course of priming effects. Priming effects increased with PM-SOA in every experiment. Moreover, these priming effects were independent of conscious visual perception of the prime. This was demonstrated in an experiment with total masking $\left(d^{\prime}=0\right)$ of the primes that nonetheless affected RT significantly. Furthermore, the time course of priming effects dissociated from the time course of prime recognition performance, suggesting that priming and prime recognition result from different underlying processes. Thus, the present and the previous study suggest a surprising similarity between indirect motor priming, priming of attention, and priming of cognitive control. In each of these cases, (1) substantial priming effects were obtained that were (2) independent from prime recognition, and showed (3) a monotonous increase with prime-mask SOA, and (4) a comparable decay when mask-target SOA increased.

\section{REFERENCES}

Abrams, R. L., \& Greenwald, A. G. (2000). Parts outweigh the whole (word) in unconscious analysis of meaning. Psychological Science, 11, 118-124.

AlLPort, A., Styles, E. A., \& Hsieh, S. (1994). Shifting intentional set: Exploring the dynamic control of tasks. In C. Umiltà \& M. Moscovitch (Eds.), Attention and performance XV: Conscious and nonconscious information processing (pp. 421-452). Cambridge, MA: MIT Press, Bradford Books.

BAND, G. P., \& VAN BoxTEL, G. J. (1999). Inhibitory motor control in stop paradigms: Review and reinterpretation of neural mechanisms. Acta Psychologica, 101, 179-211.

BREITMEYER, B. (1984). Visual masking: An integrative approach. Oxford: Oxford University Press.

Dehaene, S., Naccache, L., Le Clec'H, G., Koechlin, E., Mueller, M., Dehaene-Lambertz, G., van de Moortele, P. F., \& LE BIHAN, D. (1998). Imaging unconscious semantic priming. $\mathrm{Na}$ ture, 395, 600-604.
EIMER, M. (1999). Facilitatory and inhibitory effects of masked prime stimuli on motor activation and behavioural performance. Acta Psychologica, 101, 293-313.

EiMer, M., HOMMEL, B., \& Prinz, W. (1995). S-R compatibility and response selection. Acta Psychologica, 90, 301-313.

Eimer, M., \& SCHLAGHeCKEN, F. (1998). Effects of masked stimuli on motor activation: Behavioral and electrophysiological evidence. Journal of Experimental Psychology: Human Perception \& Performance, 24, 1737-1747.

EIMER, M., \& SCHLAGHECKEN, F. (2002). Links between conscious awareness and response inhibition: Evidence from masked priming. Psychonomic Bulletin \& Review, 9, 514-520.

FeHrer, E., \& RAAB, D. (1962). Reaction time to stimuli masked by metacontrast. Journal of Experimental Psychology, 63, 143-147.

FrancIs, G. (1997). Cortical dynamics of lateral inhibition: Metacontrast masking. Psychological Review, 104, 572-594.

Greenwald, A. G., Draine, S. C., \& ABRAMS, R. L. (1996). Three cognitive markers of unconscious semantic activation. Science, $\mathbf{2 7 3}_{2}$ 1699-1702.

HOMMEL, B. (1997). Interactions between stimulus-stimulus congruence and stimulus-response compatibility. Psychological Research, 59, 248-260.

Houghton, G., \& TipPer, S. P. (1994). A model of inhibitory mechanisms in selective attention. In D. Dagenbach \& T. H. Carr (Eds.), Inhibitory mechanisms in attention, memory, and language (pp. 53112). San Diego: Academic Press.

KANWISHER, N. (1987). Repetition blindness: Type recognition without token identification. Cognition, 27, 117-143.

KLAPP, S. T., \& HINKLEY, L. B. (2002). The negative compatibility effect: Unconscious inhibition influences reaction time and response selection. Journal of Experimental Psychology: General, 131, 255269.

Klinger, M. R., Burton, P. C., \& Pitts, G. S. (2000). Mechanisms of unconscious priming: I. Response competition, not spreading activation. Journal of Experimental Psychology: Learning, Memory, \& Cognition, 26, 441-455.

KLOTZ, W., \& NeumanN, O. (1999). Motor activation without conscious discrimination in metacontrast masking. Journal of Experimental Psychology: Human Perception \& Performance, 25, 976-992.

LaW, M. B., Pratt, J., \& Abrams, R. A. (1995). Color-based inhibition of return. Perception \& Psychophysics, 57, 402-408.

Leuthold, H., \& KoPP, B. (1998). Mechanisms of priming by masked stimuli: Inferences from event-related potentials. Psychological Science, 9, 263-269.

LoFTUS, G. R., \& MAsson, M. E. J. (1994). Using confidence intervals in within-subject designs. Psychonomic Bulletin \& Review, 1, 476-490.

Mattler, U. (2003). Priming of mental operations by masked stimuli. Perception \& Psychophysics, 65, 167-187.

Milliken, B., \& TipPER, S. P. (1998). Attention and inhibition. In H. Pashler (Ed.), Attention (pp. 191-222). Hove, U.K.: Psychological Press.

Monsell, S. (1996). Control of mental processes. In V. Bruce (Ed.), Unsolved mysteries of the mind (pp. 93-148). Hove, U.K.: Erlbaum.

NACCACHE, L., \& DehaENE, S. (2001a). The priming method: Imaging unconscious repetition priming reveals an abstract representation of number in the parietal lobes. Cerebral Cortex, 11, 966-974.

NaCcache, L., \& Dehaene, S. (2001b). Unconscious semantic priming extends to novel unseen stimuli. Cognition, 80, 215-229.

NeumanN, O., \& Klotz, W. (1994). Motor responses to nonreportable masked stimuli: Where is the limit of direct parameter specification? In C. Umiltà \& M. Moscovitch (Eds.), Attention and performance XV: Conscious and nonconscious information processing (pp. 124-150). Cambridge, MA: MIT Press, Bradford Books.

Pashler, H. E. (1998). The psychology of attention. Cambridge MA: MIT Press.

Raymond, J. E., Shapiro, K. L., \& Arnell, K. M. (1992). Temporary suppression of visual processing in an RSVP task: An attentional blink? Journal of Experimental Psychology: Human Perception \& Performance, 18, 849-860.

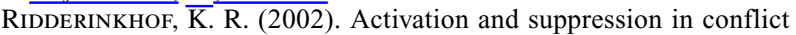
tasks: Empirical clarification through distributional analyses. In 
W. Prinz \& B. Hommel (Eds.), Attention and performance XIX: Common mechanisms in perception and action (pp. 494-519). Oxford: Oxford University Press.

Rogers, R. D., \& Monsell, S. M. (1995). Costs of a predictable switch between simple cognitive tasks. Journal of Experimental Psychology: General, 124, 207-231.

ScHLAGHECKEN, F., \& EIMER, M. (2000). A central-peripheral asymmetry in masked priming. Perception \& Psychophysics, 62, 13671382.

Schlaghecken, F., \& Eimer, M. (2002). Motor activation with and without inhibition: Evidence for a threshold mechanism in motor control. Perception \& Psychophysics, 64, 148-162.

SchmidT, T. (2000). Visual perception without awareness: Priming responses by color. In T. Metzinger (Ed.), Neural correlates of consciousness: Empirical and conceptual questions (pp. 157-169). Cambridge, MA: MIT Press.

SchmidT, T. (2002). The finger in flight: Real-time motor control by visually masked color stimuli. Psychological Science, 13, 112-118.

SPEnCE, C., \& Driver, J. (1997). On measuring selective attention to an expected sensory modality. Perception \& Psychophysics, 59, 389-403.

TIPPER, S. P. (1985). The negative priming effect: Inhibitory priming by ignored objects. Quarterly Journal of Experimental Psychology, 37A, 571-590.
VORBERG, D. (1998). Reaktion auf unbewusste visuelle Reize: Umkehr von Bahnung in Hemmung. In H. Lachnit, A. Jacobs, \& F. Roesler (Eds.), Experimentelle Psychologie (p. 386-387). Lengerich: Pabst. VorberG, D. (2002). Gibt es unbewusste Wahrnehmung, und wenn ja, warum nicht? In M. Baumann, A. Keinath, \& J. F. Krems (Eds.), Experimentelle Psychologie (p. 8). Regensburg: Roderer Verlag.

Vorberg, D., \& Lingnau, A. (in press). Time course of the negative compatibility effect with central and peripheral presentation of the effective stimuli. Perception \& Psychophysics.

Vorberg, D., Mattler, U., Heinecke, A., Schmidt, T., \& SchwarzBACH, J. (2003). Different time courses for visual perception and action priming. Proceedings of the National Academy of Sciences, $\mathbf{1 0 0}$, 6275-6280.

WENTURA, D. (2000). Dissociative affective and associative priming effects in the lexical decision task: Yes versus no responses to word targets reveal evaluative judgment tendencies. Journal of Experimental Psychology: Learning, Memory, \& Cognition, 26, 456-469.

WOLFF, P. (1989). Einfluss des maskierten Testreizes auf die Wahlreaktion auf den Maskierreiz bei Metakontrast. Paper presented at the 31st Tagung experimentell arbeitender Psychologen, Bamberg, Germany.

(Manuscript received September 22, 2003; revision accepted for publication May 26, 2004.) 